\title{
A Theoretical Framework for Assessing the Impact of Climate Change on Crop Yields
}

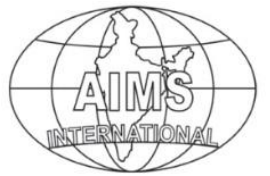

DOI: $10.26573 / 2020.14 .2 .1$

Volume 14, Number 2

May 2020, pp. 65-87

\author{
Oluwagbemiga Ojumu \\ Modupe F. Ojumu \\ Kishwar Joonas \\ Prairie View A\&M University \\ (oaojumu@pvamu.edu) \\ (mfojumu@pvamu.edu) \\ (kajoonas@pvamu.edu)
}

Agriculture's vulnerability to climate change is one of the major concerns facing the world. Extant research suggests that climate change and economic variables can have an adverse impact on crop production and yield locally and globally. The objective of this paper is to present an overview of related literature, and to propose a theoretical framework to assess the impact of climatic and economic changes on crop yields. While in agreement with the basic premise that understanding climate change is important, we also propose focus on technology as a key factor in enhancing adaption to climatic changes for improved crop yields.

Keywords: Climate Change, Temperature, Vulnerability, Agricultural Yields, Statistical Modeling, Alabama

\section{Introduction}

There is considerable research attention on the vulnerability of agriculture to climate change due to increases and depth of climate change research in different countries. Globally, agriculture is more vulnerable to climate change in comparison with water, forests, and other natural resources in the ecosystems. Therefore, an understanding of agricultural vulnerability to climate change could significantly enhance the formulation of rational and effective strategies to mitigate this impact. Several researchers, Russell (2007), Tao et al. (2011), and Wiréhn et al. (2015), all concluded that agriculture's vulnerability to climate change is one of the concerns facing the world. Concerns about the adverse impacts of climate change on agriculture are not new and are receiving attention because of the global scope and their effects on the world economy especially the regions that are traditional food baskets, producing food for the growing world population.

Some important agricultural areas of the world like the Midwestern states in the United States (known as the Corn-belt), the Northeast of Argentina, Southern Africa, and Southeast Australia have all experienced higher climate variability than other regions such as Central Africa or Europe (Schmidhuber and Tubiello, 2007). The parts of the world subject to high climatic variability are likely to expand and the rates and levels of projected warming may exceed the historical experience in some regions (Intergovernmental Panel on Climate Change IPCC, 2007). As a nation, the prospect of significant climate change has led to an unprecedented transition in climate related policy in Australian agriculture (Nelson et al., 2010). The Australian 
government has urgent demand for research to provide insights into the vulnerability of agricultural industries and rural communities (DAFF, 2005, 2006).

Climate change could positively or negatively influence crop production and yields, with respective substantial benefits or drawbacks. Higher temperatures are likely to reduce crop yield and lead to weed and pest proliferation while changes in precipitation patterns could increase the likelihood of short-run crop failures and long-run production declines. Although gains in some crops are likely, but the overall impacts of climate change on agriculture are expected to be negative (Nelson et al., 2009). As climate change continues to exert increasing pressure upon the agricultural sector of many developing and developed countries and the livelihood of people in these countries, there is an increasing need to understand and prioritize at the national and sub national levels in order to understand the regions that are most vulnerable. Schroth et al. (2017) used site-level to project regional adaptation planning for tropical commodities and reported projected losses in the production of cacao in West Africa. In a similar study, Bunn et al. (2015) examined impacts of climate change on global production of Arabica and coffee. Both studies concluded that the production losses due to climate change are threats to national economies and the regional and global supply chains of these industries that use cocoa and coffee as inputs in their production. Knox et al. (2012) studied the impact of climate change on agriculture in South Asia and Africa. The study projected the extent of production losses of major grains like wheat, maize and sorghum to reach $8 \%$ by 2050 and losses in Africa expected to reduce by $17 \%$. The study concluded that the impacts of climate change are threats to crop production and yields in regions already experiencing food insecurity. Auffhammer et al. (2012) reported the impacts of climate change on agriculture in India. The climate change induced disturbances to the monsoon recorded from 1966 to 2002 were estimated to have reduced rice yields by $4 \%$. Other studies by different researchers like Morton (2007), Harvey et al. (2014), Ayanlade et al. (2017), and Kreft et al. (2017) projected that climate change will affect local, national, and global industries. However, the impacts on the marginalized and impoverished communities in developing countries whose livelihoods are dependent upon small-scale agriculture will be most vulnerable.

Agriculture in the United States produces about $\$ 300$ billion a year in commodities. United States Department of Agriculture (USDA) explained that changes in climate and extreme weather have already occurred and are increasing the challenges for agriculture nationally and globally. Many of these impacts will continue or intensify in the future (United States Department of Agriculture, 2016). Like many other countries and regions of the world, the sensitivity of agriculture to weather and climate conditions could be severe and their impacts could have substantial direct and indirect effects on farm production and profitability in United States. The direct (i.e., abiotic) effects of changing climate conditions on crop and livestock yield, as well as through the indirect (i.e., biotic) effects arising from changes in the severity of pest pressures, availability of pollination services, and performance of other ecosystem services that affect agricultural productivity.

Globally, agriculture exists as a complex web of interactions between ecosystem services and climate change. Thus, agricultural output response to climate change is dictated by a complex set of interactions to $\mathrm{CO} 2$, temperature, solar radiation, and precipitation. Every crop species has a given set of temperature thresholds that define 
the upper and lower boundaries for growth and reproduction. Crops also have optimal temperatures for each growth phase. Most crops are grown in areas in which they are exposed to temperatures that match their threshold values with the exceptions of green house agriculture. As temperatures increase over the next century, shifts may occur in crop production areas because temperatures may no longer occur within the range, or during the critical period for optimal growth and yield of agricultural crops. In United States, the effects of climate change on agriculture will depend on changing climate conditions as well as the agricultural sector's adaptive capacity through changes in technology, demand for food, and environmental conditions such as water availability and soil quality (Intergovernmental Panel on Climate Change IPCC, 2007).

On the national level, U.S. adaptations were made during a period of relative stability in climate conditions and abundant technical, financial and natural resources. USDA, 2012, reported that adaptive actions within agricultural sectors are driven by perceptions of risk, direct productivity effects of climate change, and by complex changes in domestic and international markets, policies, and other institutions as they respond to effects within the United States and worldwide. While future agricultural adaptation will have to be undertaken in a decision environment characterized by high complexity and uncertainty driven by the sensitivity of agricultural system response to climatic variability, the complexity of interactions between the agricultural systems, non-climate stressors and the global climate system, and the increasing pace and intensity of climatic changes. Wiréhn et al. (2015) examined Swedish agricultural vulnerability to climate change using various indicator approaches at the municipal level. The results indicated that 34 of 36 method combinations differ significantly from each other. The result suggests that representing agricultural vulnerability in a single composite index might be insufficient to guide climate adaptation.

In spite of these, agriculture in the United States and other industrialized countries is expected to be less vulnerable to climate change than agriculture in developing nations, especially in the tropics, where farmers' adaptive capacity is limited (IPCC, 2007). The direct and indirect biophysical impacts of climate on agriculture also affect the profitability of farming activities and lead to changes in land use, regional investment, infrastructure allocations, and the well-being of rural communities. This paper will develop preliminary insights into the frameworks and models that assess impacts of climate change on the U.S. agricultural sector and use the results to generate wider international interest, due to United States' long history of leading applied research in the agriculture. To accomplish this, this paper will adapt Schroth et al. (2017) who used site-level to project regional adaptation planning to mitigate climate impacts. Wiréhn et al. (2015) also used municipal level data to infer Swedish agricultural vulnerability to climate change. Therefore, this study will specifically focus on select crops that are cultivated in the state of Alabama. Using Alabama data, this study will assess the impact of changes in selected climatic variables, production input like fertilizer used, and technology on crop yield. This will shed light on the farmers' productive efficiency and adaptive capacity to changes in the variables and the identify the required mitigation strategies needed to meet increasing domestic and world food demand from the pressures of a rapidly growing US and global population as farmers deal with changing climatic variables. 


\subsection{Climate in Alabama}

Alabama is a southeastern state in United States. In Alabama, agriculture is mainly rainfed (Wagaw et al., 2009) and the annual precipitation averages from about 1651 $\mathrm{mm}$ in the south to $1356.2 \mathrm{~mm}$ in the north (Ning \& Abdollahi, 2004). Only 106,860 acres out of 3,142,958 acres of cropland are irrigated or about $3.4 \%$ of total farmed acres (United States Department of Agriculture USDA, 2007). Increased rainfall and the possibility of more severe storm events than in the past could lead to increased risks of flooding. Increased temperature could lead to polar ice melting and sea level rising, which could affect Alabama's coastline, associated wetland areas and other agricultural land. The four major crops in Alabama (Appendix S) are cotton (Gossypium hirsutum), corn (Zea mays), peanut (Arachis hypogaea) and soybean (Glycine max) ranked from the highest to the lowest in the order of their value of production (United States Department of Agriculture USDA, 2008). These crops are grown in all the counties in Alabama and their geographic distribution is shown in Geographic Information Science (GIS) generated maps in Appendices A, B, C and D).

Alabama's climate is characterized by relatively mild winters, hot summers, and year-round precipitation. This generally warm, humid climate is as a result of its mid-latitude location and proximity to the Gulf of Mexico. The location also produces the often turbulent weather patterns that regularly bring tornadoes and hurricanes to the state. Temperatures tend to be slightly higher in the southern half of the state than in the northern half, as can be observed, comparing the temperature records for the cities of Mobile and Huntsville. Mobile, located in the south, has an average minimum daily temperature in January of approximately $4.39^{\circ} \mathrm{C}$, whereas Huntsville, located in the north, has an average minimum daily temperature in January of approximately $-1.5^{\circ} \mathrm{C}$. Also, Mobile has an average maximum daily temperature in July of approximately $32.9^{\circ} \mathrm{C}$, and Huntsville has an average maximum daily temperature in July of approximately $30.3^{\circ} \mathrm{C}$ (Chaney, 2007). Precipitation patterns tend to be higher in the southern half of the state than in the northern half, with the Mobile area averaging up to 1673.86 millimeters and the Huntsville area averaging 1447.8 millimeters. In south Alabama, higher temperatures and precipitation patterns combine to produce a considerable difference in the length of the growing season for agricultural production across the state, which varies from approximately 200 days per year in the north to approximately 250 days per year in the south (Chaney, 2007).

This study will abstract the impact of climate fluctuations on crop yields in Alabama to overall impact of climate change on crop yield United States using weather and biophysical data in Alabama from 1970 to 2015. The specific objectives are to: i) assess the strength of the relationship between crop yield and selected climatic variables: minimum temperature, maximum temperature, precipitation, and two other variables: fertilizer used and technology, and ii) assess farmers' adaptive capacity to such changes in Alabama. To address the research objectives, it is hypothesized that crop yield is likely to be negatively related to maximum temperature and positively related to minimum temperature, fertilizer used and technology. In addition, crop yield is likely to be either positively or negatively related to precipitation. The study assesses the impact of changes in selected climatic variables, inputs, and technology on crop yield. It also sheds light on the farmers' 
productive efficiency and adaptive capacity to such changes and the required mitigation strategies.

\section{Theoretical Framework}

This section discusses climate change, models of climate change, simulated climate change empirical studies at the global and country levels, and historical climate change empirical models at the global, country and state levels.

\subsection{Climate Change}

Changes in temperature coupled with variable precipitation could reduce productivity of crops, and these effects will outweigh the adopted production systems. The effects will vary among annual and perennial crops, and regions of the United States; however, all production systems will be affected in varying degrees by climate change. Generally, agricultural systems depend on reliable water sources, and the pattern and potential magnitude of precipitation changes if not well understood, will add considerable vulnerability and uncertainty to agriculture.

Greenhouse gases in the form of carbon dioxide $\left(\mathrm{CO}_{2}\right)$, methane $\left(\mathrm{CH}_{4}\right)$, nitrous oxide $\left(\mathrm{N}_{2} \mathrm{O}\right)$, and chlorofluorocarbons (CFCs), trap infrared radiation from the Earth's surface and cause the greenhouse effect. The greenhouse effect is a natural ecological process which contributes to maintaining a stable temperature and climate on Earth. However, human activities, such as fossil fuel combustion, deforestation, and some chemical manufacturing activities have led to an increased concentration of greenhouse gases. Consequently, more infrared radiation has been captured in the atmosphere, causing changes in the air temperature, precipitation patterns, sea level rise, and melting of polar glaciers. Such changes are referred to as climate change (IPCC, 2007).

\subsection{Climate Change Models}

Several studies assessed the impact of climate change on agriculture, especially the impact on crop production. These studies used different models and approaches to assess, measure, and simulate the impact of climate change on agriculture. Smit et al. (1988) identified the impacts using crop yield analysis, spatial analysis, and agricultural systems analysis as the three main approaches for studying the implications of global climate change for agriculture. The crop yield analysis consisted of estimating the effects of altered environments on crop productivity levels, spatial analysis examined the implications of climate change on the regions and lands suitable for agricultural production, while agricultural systems analysis assessed the impacts of climate change on multiple agricultural activities and on the functioning of the agricultural food sector, including prices, trade patterns, and employment.

The Food and Agriculture Organization FAO (1996) developed the crop suitability approach, also referred to as the agro-ecological zoning (AEZ) approach, in which the suitability of various land and biophysical attributes to crop production was assessed. This approach used crop characteristics, existing technology, and soil and climate factors to determine the suitability of crop production to various areas. Researchers du Toit et al. (2001) and Xiao et al. (2002) also used the AEZ model to predict the impact of changing climatic variables on potential agricultural output and 
cropping patterns by including climate as a major determinant of the suitability of agricultural land to crop production. However, Mendelsohn and Tiwari (2000) emphasized one disadvantage of the AEZ methodology in that it is not possible to predict final outcomes without explicitly modeling all the relevant components. The omission of one major factor, such as existing technology or soil factor, could substantially affect the model's predictions.

Mendelsohn et al. (1994) used the AEZ approach and the production function which included climatic variables such as temperature, rainfall, and carbon dioxide $\left(\mathrm{CO}_{2}\right)$ as inputs. Changes in yield were induced by changes in climatic variables, and then measured and analyzed at different testing sites. Furthermore, the estimated changes in yield caused by changes in environmental variables were aggregated to reflect the overall impacts under various climate change scenarios.

\subsection{Simulated Global Models}

$\mathrm{Li}$ et al. (2009) assessed the impact of global drought risk on major crop production for current and future climates through an integrated approach which included predicting the impacts of future climate change scenarios on the yields of rice (Oryza sativa), maize, wheat (Triticum aestivum), barley (Hurdeum vulgare), sorghum (Sorghum bicolor), and soybean. Globally, the results showed an increase in drought disaster affected areas with rising global temperature by 2100 . As a result, the rates of yield reduction related to drought disaster for major crops would increase significantly with future climate change by more than $50 \%$ in 2050 and almost $90 \%$ in 2100 for the major crops.

Parry et al. (2004) analyzed the global consequences of climate scenarios on crop yields using climate change scenarios developed from Hadley Center Coupled Model, version 3 (HadCM3) global climate model under the IPCC Special Report on Emissions Scenarios (SRES) A1F1, A2, B1, and B2 (Appendix U for a definition of these scenarios). The results revealed that the A1F1 scenario, with its large increase in global temperatures, exhibited the greatest decreases both regionally and globally in yields, especially by the 2080 s.

Hijmans (2003) examined the effect of climate change on global potato (Solanum tuberosum) production, using a simulation model and a grid with monthly climatic data for the 1961-1990 period. The model projected conditions for the 2010-2039 and 2040-2069 periods in order to calculate potential yields. An increase of between 2.1 and $3.2^{\mathrm{c}} \mathrm{O}$. in global (excluding Antarctica) average temperature was predicted between the 1961-1990 and 2040-2069 periods, with decreases in global potential potato yield of 18 to $32 \%$, without technology and of 9 to $18 \%$, with technology. In contrast, yields would increase at high latitudes because of a lengthening of the growing season. However, in regions such as parts of Algeria, Morocco, China, and South Africa, yields would increase as a result of a warmer climate which would allow growing a winter crop, instead of an autumn or spring crop.

Zhai and Zhuang (2009) used a dynamic Computable General Equilibrium (CGE) model, calibrated to the Global Trade Analysis Project (GTAP) version 7, to investigate the potential impacts of climate change on agriculture and the world economy, with a special focus on Southeast Asia. The results suggested that the aggregate impacts of agricultural damage caused by climate change on the global economy were moderate. Moreover, the results revealed that given the anticipated 
declining agricultural share in the economy, a reduction in agricultural productivity would have small, but non-negligible negative impacts on Southeast Asia's economic output. Also, the negative effects were expected to be less for Singapore and Malaysia because of their more diversified economic structure, but greater for Philippines, Indonesia, Thailand and Vietnam, countries with less diversified economies.

Barrios et al. (2004) examined the impact of climatic change on the level of total agricultural production of developing countries in Sub-Sahara Africa (SSA) and Non-Sub-Sahara Africa (NSSA), using a new cross-country panel climatic dataset in an agricultural production framework. The results showed that climate, measured as changes in country-wide rainfall, and temperature, has been a major determinant of agricultural production in SSA. In contrast, NSSA countries appeared not to be affected by climate in the same manner. Simulations using such estimates suggested that the detrimental changes in climate since the 1960s can account for a substantial portion of the gap in agricultural production between SSA and the rest of the developing world.

Diaz-Ambrona et al. (2004) investigated the impact of traditional management practices on maize productivity of subsistence farming systems in the dry subtropical environment of Honduras (Central America), using a model designed to simulate cropping systems (CropSyst). Model estimates were compared with yield, phenology, and soil organic matter under a wide range of weather, rotations, cultivars, management practices, and soils. The results of the investigation showed that under current management practices, simulated future climate change scenarios increased yield variability and reduced yield by 0 to $22 \%$. They also found that crop growing opportunities and the crop maturity date were particularly sensitive to climate change. However, they concluded that the predicted impacts of climate change on maize yield of $0-22 \%$ decrease might add significantly to the challenge of ensuring food security.

Zhai et al. (2009) examined the potential long-term impacts of global climate change on agricultural production and trade in the People's Republic of China (PRC). Using an economy-wide, global Computable General Equilibrium (CGE) model, simulations of the scenarios of global agricultural productivity change induced by climate change up to 2080 were estimated. The results suggested that, with the anticipated decline in the agricultural share of gross domestic product, the impact of climate change on the PRC's macro-economy would be moderate. The food processing subsectors were predicted to bear the brunt of losses from the adverse agricultural productivity effects caused by climate change. Production of some crop sectors such as wheat, in contrast, is likely to expand due to increased demand from other regions of the world.

Makhado (1996) assessed the effect of climate change on corn production in Zimbabwe using the Global Circulation Models (GCMs) and crop growth simulation model CERES-Maize. The results suggested that corn productivity in Zimbabwe would reduce significantly under non-irrigated or irrigated conditions in some regions of agricultural production. Specifically, ambient temperature increases which shorten the crop growth period, particularly the grain-filling period, were responsible for the reductions in corn yields. The results further indicated that the effects of climate change on corn production could pose an unacceptable risk to farmers since 
financial costs may be prohibitive to the adaptation options available. Srivani et al. (2007) simulated the impact of future climate change on the productivity of rice at three different time periods, 2020, 2050 and 2080 in Tamil Nadu, India, using different $\mathrm{CO}_{2}$ concentration levels. Future changes in temperatures and precipitation for the years 2020, 2050 and 2080 were acquired from Hadley Center Coupled Model, version 3 (HadCM3) run outputs and integrated with the 2000 base year data to create weather files to run the INFOCROP model in order to predict the yield of the study crop under changing environments. The projection on future climate indicated an alarming increase in both minimum and maximum temperature coupled with variability in rainfall which would have greater impact on rice production. In addition, crop duration would be shortened, anthesis (flowering period) dates were expected to be advanced, and translocation of photosynthesis might be inefficient, hence, a huge reduction in the crop productivity

Lobell et al. (2004) assessed the impact of climatic changes on Mexican wheat yield trends and measured the true yield progress due to crop breeding and management changes, using both simulation and statistical modeling to assess climatic impacts. The results indicated a $25 \%$ increase in wheat over the past two decades attributed to climatic trends in Northwest states, in particular cooling of the growing season night time temperatures. Tuttolomondo et al. (2009) analyzed the direct and indirect effects of climatic changes such as rainfall, minimum and maximum temperatures, and sunlight on average barley yields in four selected rural areas of Italy for a period of 99 years. The CERES model was used to: simulate barley growth and development; evaluate the effects of climate change on barley yields; and analyze the inter-annual variability in production. The results showed that yield variability increased slightly with a rise in the variability of both temperature and rainfall with greater effects in the north and diminishing effects in the south and island areas.

Travasso et al. (2009) assessed the impact of future climate, 2081-2090, on regional corn yields through a crop simulation model in Argentina, with and without considering the fertilization effect of $\mathrm{CO}_{2}$. Results obtained under future scenarios indicated that, without considering the effect of $\mathrm{CO}_{2}$, the impact on yields would be negative in most regions, attaining mean reductions of 9 and 6\% under SRES A2 and B2 scenarios respectively. However, yield changes could range between increases of $46 \%$ under $\mathrm{B} 2$ and decreases of $17 \%$ under $\mathrm{A} 2$. In contrast, the effect of $\mathrm{CO}_{2}$ led to increases in corn yields by $19 \%$ under A2 and $11 \%$ under B2, although negative impacts could still occur. The greater impact of SRES A2 was attributed to the stronger increase in projected temperature of about $2-3^{\circ} \mathrm{C}$ in maximum temperatures and $3^{\circ} \mathrm{C}$ in minimum temperatures, exceeding the projections under SRES B2 by $1^{\circ} \mathrm{C}$.

Lee et al. (2009) predicted crop yields in California Central Valley, using the daily version of Century (DAYCENT) model to stimulate changes in yield of alfalfa (Medicago sativa), cotton, corn, winter wheat, tomato, and rice under A2 (mediumhigh) and $\mathrm{B} 1$ (low) $\mathrm{CO}_{2}$ emission scenarios, using a total of 18 climate change predictions for the two scenarios. The results of the comparison, using five-year moving averages from 1953-2097, indicated that changes in yield were highly variable depending on the climate change scenarios across times. Furthermore, the variability in crop yield changes tended to increase toward the end of the century, 
showing that future climate had a broad range of impacts on crop yields. Overall, the results suggest that climate change will decrease crop yields in the long-term, particularly for cotton, unless greenhouse gas emissions and resulting climate change is curbed and/or adaptation of new management practices and improved cultivars occurs.

Goldblum (2009) considered the potential county-scale impact of climate change on corn and soybean yield in the state of Illinois from 1927-2009. Monthly regional General Circulation Model (GCM) predictions were compared with the monthly climate variables to which corn and soybean yields are sensitive in predicting crop yield under future climate. The results revealed a negative correlation between corn yield and July/August temperature in most of the state, and a positive correlation with precipitation from the previous September (in the central part of the state) and July and August precipitation in most of the northern and southern Illinois, respectively. In addition, soybean yield showed a negative correlation with mean monthly temperature in central and southern Illinois during the summer, and a positive correlation with July and August precipitation in the same regions.

Deressa and Hassan (2009) assessed the economic impact of climate change on Ethiopian agriculture while analyzing farmers' adaptations to mitigate the potential impact of climate change, using a sample of 1,000 farmers randomly selected from different agro-ecological zones of the country. The Ricardian approach was used in this study, under the assumption that each farmer would seek to maximize net farm revenues by choosing inputs subject to climate, soils, and economic factors. Net crop revenue per hectare was regressed against climate, household and soil variables. The results indicated that the climatic, household, and soil variables had a significant impact on the net revenue per hectare for Ethiopian farmers. Moreover, predicted climate scenarios from three models for 2050 and 2100 revealed a reduction in crop net revenue per hectare by 9.71 to $303.27 \%$ in 2050 and 103.395 to $418.01 \%$ in 2100 , with the reduction in net revenue per hectare by the year 2100 higher than that of 2050.

Yingjie et al. (2008) examined the impacts of temperature change, agricultural input, and planting area on grain production for different regions of China for a twenty- year period, 1984-2003, using a regression model in their analysis with crop yield as the dependent variable and agricultural inputs and temperature as the independent variables. The findings were that climate warming promoted grain yield in Northeast China, but to a lesser extent suppressed yield in North China, Northwest China and Southwest China, but showed no obvious effects on yield in East China and Central-South China. In addition, the increase in agricultural inputs facilitated grain production during the early stage but showed no significant effect in later stages.

Ajetomobi and Abiodun (2010) employed a statistical model to investigate the relationship between cowpea (Vigna unguiculata) yield and temperature, precipitation, and time trend (proxy for technological change and innovations) for the 1961-2006 period in the 20 largest cowpea producing states in Nigeria. The response of cowpea yield to climate change varied from one geographical location to the other. Furthermore, the results indicated a negative and significant relationship between cowpea yield and increased temperature in six of the states, five in the north and one in the south. Similarly, the relationship between yield and increased 
precipitation was negative and significant in the northern states, except one. Also, the results indicated a negative correlation between precipitation and cowpea yield in the north whereas increase in precipitation increased yield in the south.

For the simulated models, Li et al. (2009), Parry et al. (2004), and Makhado (1996) projected yield reduction for soybean, maize and other major crops with rising temperature with future climate change. Srivani et al. (2007) predicted a huge reduction in rice productivity as a result of projected increase in both minimum and maximum temperature while Tuttolomondo et al. (2009) revealed greater yield variability for wheat with a rise in both temperature and rainfall variability. The findings of Kurukulasuriya and Mendelsohn (2008), Deressa and Hassan (2009), Molua and Lambi (2007), and Gwimbi (2009) revealed that decreased precipitation or increased temperatures reduced cotton yield, which led to a reduction in net revenues in Africa but they also suggested that the negative impact could be abated through adopting the right technology. Yingjie et al. (2008), Ajetomobi and Abiodun (2010), Kucharik and Serbin (2008), Lobell et al. (2007), Changnon and Hollinger (2003), and Hu and Buyanovsky (2003) all used multiple regression to analyze yield as a function of the climatic variables and socio-economic variables. These models served as the theoretical framework on which this study was based.

\subsection{Global Studies and Historical Models}

Lobell and Field (2007) analyzed the impacts of climate, soil and management on the average global yields for the world's six most widely grown crops: wheat, rice, maize, soybeans, barley, and sorghum for the 1961-2002 period. Multiple regressions were tested, with first differences in yield as the dependent variable, and first-differences of minimum temperature, maximum temperature, and precipitation as independent variables. The results indicated that at least $29 \%$ of the variance in year-to-year yield changes was explained by the independent variables for all crops. However, the global yields of wheat, corn, and barley responded negatively to increased temperature which resulted in combined losses of about $\$ 5$ billion per year, as of 2002. In contrast, it was inferred that potential impacts of temperature increases might have been countered by adaptive measures taken by farmers such as changes in planting dates or use of different cultivars. On the whole, the results suggested that recent climate trends, attributable to human activity, had a discernible negative impact on global production of several major crops.

Frich et al. (2002) examined changes in frequency and/or severity of climatic extremes during the second half of the 20th century using indicators such as daily maximum and minimum temperature series, and daily totals of precipitation which represented changes in all seasons of the year. The results indicated that the world became both warmer and wetter for the global land areas examined, although large areas such as Africa and South America were not represented. Heavy rainfall events have become more frequent and cold temperature extremes less frequent during the second half of the 20th century. These observed changes in climatic extremes are consistent with expected changes under enhanced greenhouse conditions.

Similarly, Kurukulasuriya and Mendelsohn (2008) examined the impact of climate change on cropland in Africa, using the Ricardian cross-sectional approach, and also predicted impacts of future scenarios from climate models. The study confirmed that current climate affects the net revenues of farms across Africa because African farms 
are sensitive to climate, especially temperature. The findings were consistent with those of Deressa and Hassan (2009). They also found that farm net revenues were lower in places with higher temperatures. The predictions of the impacts of future scenarios from climate models further showed that irrigated farms would benefit slightly across all scenarios, dryland farms would depend on such scenarios, and harsh scenarios would lead to large losses. Moreover, the impacts are expected to be evident as early as 2020 and become larger over time as warming increases.

Schlenker and Lobell (2010) developed a robust model of yield response to climate change for several key African crops by combining historical crop production and weather data into a panel analysis. The results indicated that by midcentury, the mean estimates of aggregate production changes in Sub-Saharan Africa under the panel model specification were $-22 \%,-17 \%,-17 \%,-18 \%$, and $-8 \%$ for maize, sorghum, millet (Eleusine coracana), groundnut (Arachis hypogaea), and cassava (Manihot esculenta), respectively. Also, in all cases, except cassava, there was a $95 \%$ probability that damages exceeded $7 \%$, and a $5 \%$ probability that they exceeded $27 \%$. Moreover, countries with the highest average yields such as South Africa and Zimbabwe had the largest projected yield losses, suggesting that wellfertilized modern seed varieties are more susceptible to heat related losses.

Olesen and Bindi (2004) illustrated the trends in European agriculture, as a result of climate change, by the development of wheat yield over the past three decades. Wheat yields increased rapidly in the north-western part of Europe (e.g. UK and France) while yields in both the Nordic (e.g. Norway) and the Mediterranean region (e.g. Italy) increased at a much slower rate due to adverse climatic conditions in these regions. Also the increase in maize area in Denmark was attributed to the warming that has occurred over the past two decades.

\subsection{Country-Level Studies}

Peng et al. (2004) analyzed weather data from 1979-2003 and examined temperature trends and the relationship between rice yield and temperature, using data from irrigated field experiments conducted at the International Rice Research Institute Farm (IRRIF), Philippines, from 1992-2003. They reported an increase in annual mean maximum and minimum temperatures by 0.35 and $1.13^{\circ} \mathrm{C}$, respectively, for the 1979-2003 period. Also, they established a close linkage between rice grain yield and mean minimum temperature during the dry cropping season, January to April. Furthermore, grain yield declined by $10 \%$ for each $1 \mathrm{C}$ increase in growing season minimum temperature in the dry season while the effect of maximum temperature on crop yield was insignificant. The study provided direct evidence of decreased rice yields from increased nighttime temperature associated with global warming.

Deressa and Hassan (2009) assessed the economic impact of climate change on Ethiopian agriculture while analyzing farmers' adaptations to mitigate the potential impact of climate change, using a sample of 1,000 farmers randomly selected from different agro-ecological zones of the country. The Ricardian approach was used in this study, under the assumption that each farmer would seek to maximize net farm revenues by choosing inputs subject to climate, soils, and economic factors. Net crop revenue per hectare was regressed against climate, household and soil variables. The results indicated that the climatic, household, and soil variables had a significant impact on the net revenue per hectare for Ethiopian farmers. Moreover, predicted 
climate scenarios from three models for 2050 and 2100 revealed a reduction in crop net revenue per hectare by 9.71 to $303.27 \%$ in 2050 and 103.395 to $418.01 \%$ in 2100 , with the reduction in net revenue per hectare by the year 2100 higher than that of 2050. On the other hand, the damage posed by climate change would increase with time unless the negative impact is abated through technology.

The findings of Molua and Lambi (2007) further corroborated Deressa and Hassan (2009), and Kurukulasuriya and Mendelsohn (2008). Molua and Lambi (2007) examined the impact of climate change on crop farming in Cameroon using the Ricardian cross-sectional approach. The analysis indicated that net revenues fell as precipitation decreased or temperatures increased across all the surveyed farms. The study reaffirmed, that agriculture in Cameroon, and in any other African country, is often limited by seasonality and the availability of moisture.

Yingjie et al. (2008) examined the impacts of temperature change, agricultural input, and planting area on grain production for different regions of China for a twenty- year period, 1984-2003, using a regression model in their analysis with crop yield as the dependent variable and agricultural inputs and temperature as the independent variables. The findings were that climate warming promoted grain yield in Northeast China, but to a lesser extent suppressed yield in North China, Northwest China and Southwest China, but showed no obvious effects on yield in East China and Central-South China. In addition, the increase in agricultural inputs facilitated grain production during the early stage but showed no significant effect in later stages. However, they concluded that climate warming had positive effects on grain production in Northeast China because of the adoption of appropriate adaptive methods such as fertilizer inputs, use of improved seed, and irrigation.

Gwimbi (2009) analyzed climate change and its impact on cotton production in the Gokwe district of Zimbabwe, using a time series analysis of temperature and rainfall for a period of 30 years. Also, correlation tests between the independent variable climate and the dependent variable cotton output were assessed in order to determine the nature and strength of the relationship. He found out that cotton production levels declined as precipitation decreased and temperatures increased across the district. The results further showed that farmers are highly vulnerable to climate change and therefore, need to invest in climate adaptation strategies to help them cope better and reduce their vulnerability to climate change.

Ajetomobi and Abiodun (2010) employed a statistical model to investigate the relationship between cowpea (Vigna unguiculata) yield and temperature, precipitation, and time trend (proxy for technological change and innovations) for the 1961-2006 period in the twenty largest cowpea producing states in Nigeria. The response of cowpea yield to climate change varied from one geographical location to the other. Furthermore, the results indicated a negative and significant relationship between cowpea yield and increased temperature in six of the states, five in the north and one in the south. Similarly, the relationship between yield and increased precipitation was negative and significant in the northern states, except one. Also, the results indicated a negative correlation between precipitation and cowpea yield in the north whereas increase in precipitation increased yield in the south. Moreover, the coefficient of the trend variable was positive and significant for all the states showing that as the years went by, the farmers were also adopting new measures to cope with the negative effect of climate change. 
Harrison (2010) analyzed the impact of temperature, precipitation and yield on the production of corn and red kidney bean (Phaseolus vulgaris) for Cayo and Orange Walk districts in Belize, Central America, for the 1986-2008 period, using historical data. Ordinary Least Square multiple regression was used to test the strength of the relationship between total corn and red kidney bean production and four independent variables: temperature, precipitation, mechanized yield, and non-mechanized yield. The results showed that maximum temperature suppressed corn and red kidney bean production for the dry season in both districts, while increasing corn and red kidney bean production in Cayo district for the wet season. Also, minimum temperature increased corn and red kidney bean production in Cayo and Orange Walk districts respectively. Moreover, precipitation decreased corn and red kidney bean production in both districts during the wet and dry seasons.

Chen et al. (2004) estimated the impacts of climate change on yield of major U.S crops using panel data time-series techniques. The effects of climate on yield levels and variances were shown to vary depending on the crop. For sorghum, higher rainfall and temperatures increased yield, and increased yield variability. For corn, precipitation and temperature results were found to have opposite effects on yield levels and variability. Higher rainfall caused corn yield to rise, and yield variability to decrease. Temperature had the reverse effects on corn yield and variability. For sorghum, higher temperatures reduced yield but also variability. Higher rainfall increased sorghum yield and variability.

Kucharik and Serbin (2008) focused on quantifying the previous impact of temperature and precipitation trends on corn and soybean trends across Wisconsin from 1976 through 2006, using multiple regression models with minimum temperature, maximum temperature, average temperature, and precipitation as independent variables and corn and soybean yield trends as dependent variables. They found that both corn and soybean yield trends were enhanced in counties that experienced a trend toward cooler and wetter conditions during the summer. The results further suggested that for each additional degree $\left(1^{\circ} \mathrm{C}\right)$ of future warming during summer months, corn and soybean yields could potentially decrease by 13 and $16 \%$ respectively. In contrast, if modest increases in total summer precipitation by about $50 \mathrm{~mm}$ were to occur, yields might be boosted by $5-10 \%$, counteracting a portion of the negative effects associated with increased temperature.

\subsection{State and Sub-Region Studies}

Lobell et al. (2007) analyzed the relationship between crop yield and three climatic variables (minimum temperature, maximum temperature, and precipitation) for twelve major Californian crops: wine grapes, lettuce (Lactuca sativa), almonds, strawberries (Fragaria spp), table grapes, hay, oranges, cotton, tomatoes, walnuts, avocado, and pistachios (Pistacia vera), for the 1980-2003 period. The months and climatic variables of greatest importance to each crop were used to develop multiple regressions relating yield to climatic conditions for the crops. They discovered that more than two-thirds of observed yield variance could be explained by using only 2-3 variables for most crops. Furthermore, high February minimum temperature and precipitation decreased hay yields while warmer May maximum temperature of up to $28^{\circ} \mathrm{C}$ and warmer night June temperatures increased cotton yield. 
Climate effects on corn yield and the yield differences caused by different intraseason distributions of rainfall, temperature, and daily temperature range were examined by $\mathrm{Hu}$ and Buyanovsky (2003) for central Missouri, using corn yield and climate data for the 1895-1998 period. The results showed that the growing season distributions of rainfall and temperature for high-yield years were characterized by less rainfall and warmer temperature in the planting period, a rapid increase in rainfall, and higher rainfall and warmer temperatures during germination and emergence. In contrast, opposite variations in rainfall and temperature in the growing season corresponded to low yields.

Changnon and Hollinger (2003) conducted field tests on agricultural test plots in central Illinois, a typical Corn Belt area, to determine how corn yields responded to varying levels of added rainfall $(+10 \%,+25 \%$, and $+40 \%)$ during the growing season for a five-year period, 1988, 1991 and 1994. The plot results showed that only small average increases in corn yields occurred from growing season rain additions in the $10 \%$ to $40 \%$ range, except in dry years. Furthermore, they inferred that crop yield regression models, incorporating the same rain increases predicted greater yield increases than in the field tests. Hence, it was suggested that future yields projected for a wetter climate using yield-weather models may be over-estimated.

For the simulated models, Li et al. (2009), Parry et al. (2004), Makhado (1996) projected yield reduction for soybean, maize and other major crops with rising temperature with future climate change. Srivani et al. (2007) predicted a huge reduction in rice productivity as a result of projected increase in both minimum and maximum temperature while Tuttolomondo et al. (2009) revealed greater yield variability for wheat with a rise in both temperature and rainfall variability.

Rosenzweig et al. (1995, 2002) predicted a doubling of US corn production losses in the Midwest as a result of increased precipitation and increased global mean temperature in the next thirty years. Also, Cai et al. (2009) showed that the mean yield of rain fed corn would decline by 23-34\%. Furthermore, Chen et al. (2004) showed that higher rainfall caused a rise in corn yield while higher temperatures reduced yield in the US.

In Wisconsin, Kucharik and Serbin (2008) revealed that increases in maximum temperature would lead to a decrease in corn and soybean yields while increases in precipitation would increase yield, counteracting some of the negative effects of increased temperature, but in California, Lobell et al. (2007) showed that cotton yield increased when warmer maximum temperature was up to $28^{\circ} \mathrm{C}$. However, $\mathrm{Hu}$ and Buyanovsky (2003) showed that less rainfall and warmer temperatures in the planting period, higher rainfall and warmer temperatures during germination would lead to higher yields of corn in Missouri.

The findings of Kurukulasuriya and Mendelsohn (2008), Deressa and Hassan (2009), Molua and Lambi (2007), and Gwimbi (2009) revealed that decreased precipitation or increased temperatures reduced cotton yield, which led to a reduction in net revenues in Africa but they also suggested that the negative impact could be abated through adopting the right technology. On the other hand, Makhado (1996) indicated that the negative impact of climate change on corn production posed a high risk to farmers due to the financial cost of the adaptation options available.

In China, Yingjie et al. (2008) found that climate warming had different effects on grain production in different parts of China, suppressing or promoting yields but the 
positive effect was attributable to technology. Similarly, Harrison (2010) showed that maximum temperature suppressed corn and red kidney bean production in Belize, minimum temperature increased corn and red kidney bean production, and precipitation decreased corn and red kidney bean production. The results show that different regions and crops are affected differently by changes in the climatic variables. For instance, in China, climate warming had different effects on grain production in different parts of the country. The findings were that climate warming promoted grain yield in Northeast China, suppressed yield in North China, Northwest China and Southwest China, and showed no obvious effects on yield in East China and Central-South China.

Yingjie et al. (2008), Ajetomobi and Abiodun (2010), Kucharik and Serbin (2008), Lobell et al. (2007), Changnon and Hollinger (2003) and Hu and Buyanovsky (2003) all used multiple regression to analyze yield as a function of the climatic variables and socio-economic variables. These models served as the theoretical framework on which this study was based. The frameworks for conceptualizing and analyzing the impact of climate on agricultural yield have their origins in various academic disciplines and professional fields of practice. The research has proven difficult and somewhat controversial to organize into classification systems. Some include works done by the authors such as Adger (2006), Adger et al. (2007), Adger and Vincent, (2005), and Nelson et al. (2007a). These various studies show that crop yields to climate variations is situation specific and that there can be no single, unified or general purpose response, there is an evolution from linear impact assessments towards more integrated, systems approaches to measuring yield response to climate change. In summary 'yield response is dependent on vulnerability, which in turn is place and time dependent. Furthermore, Adger (2006) added that it is specific to include place, time and the perspective of those assessing the climate impacts.

\section{Methodology}

This section discusses the scope of a proposed study; the theoretical and estimated models; data collection and source; hypotheses and expected signs of regressor coefficients; and specification of variables; and data analysis. The proposed study will focus is on Alabama and it will cover four major crops: cotton, corn, peanut and soybean, using historical secondary data for the crop yields and data and the selected climatic variables for the $1960-2015$ period. This period was chosen because of the availability of consistent time-series data on the dependent variable and the independent variables.

\subsection{The Theoretical Model}

The theoretical framework for this study is based on the empirical work by Yingjie et al. (2008), Ajetomobi and Abiodun (2010), Kucharik and Serbin (2008), Lobell et al. (2007), Changnon and Hollinger (2003), and Hu and Buyanovsky (2003). They estimated crop yield as a function of minimum temperature, maximum temperature, precipitation and selected agricultural inputs.

\subsection{The Estimated Model}

$\mathrm{Y}_{\mathrm{t}}=\alpha_{0}+\alpha_{1} \operatorname{Tmax}_{\mathrm{t}}-\alpha_{2} \operatorname{Tmin}_{\mathrm{t}} \pm \alpha_{3} \mathrm{PRE}_{\mathrm{t}}+\alpha_{4}$ Fert $_{\mathrm{t}}+\alpha_{5} \mathrm{TECH}_{\mathrm{t}}+u \ldots \ldots \ldots \ldots \ldots \ldots \ldots . .1$

$\mathrm{Y}=$ Yield per acre in bushel or pound per acre 
$\alpha_{\mathrm{i}}=$ Regressor coefficients $(\mathrm{i}=1, \ldots, 5)$

$\mathrm{t}=1960-2015$

$\mathrm{Tmin}_{\mathrm{t}}=$ Average annual minimum temperature in degrees Celsius

$\operatorname{Tmax}_{\mathrm{t}}=$ Average annual maximum temperature in degrees Celsius

$\mathrm{PRE}_{\mathrm{t}}=$ Average annual precipitation in millimeters

Fert $_{\mathrm{t}}=$ Fertilizer used in tons/acre

$\mathrm{TECH}_{\mathrm{t}}=$ Technology (time used as proxy)

$u=$ Error term

The hypotheses and expected signs of Regressor coefficients are shown below in Table 1.

Table 1 Hypotheses and Expected Signs of Regress or Coefficients

\begin{tabular}{|c|c|l|}
\hline Coefficient & Expected Signs & \multicolumn{1}{|c|}{ Impact on Yield/Acre } \\
\hline$\alpha_{1}$ & + & Promotes yield \\
\hline$\alpha_{2}$ & - & Suppresses yield \\
\hline$\alpha_{3}$ & \pm & Promotes or suppresses yield \\
\hline$\alpha_{4}$ & + & Promotes yield \\
\hline$\alpha_{5}$ & + & Promotes yield \\
\hline
\end{tabular}

\subsection{Data Collection and Source}

Secondary data on annual yields of corn, cotton, soybean, and peanut for Alabama will be collected from the National Agricultural Statistics Service Database for the 1960-2015 period. Data on daily precipitation, daily maximum temperature and daily minimum temperature for the 1960-2015 period will be obtained from Blackland Research and Extension Center, Texas. The annual average maximum and minimum temperatures will be calculated by averaging the daily totals for each year. The annual average precipitation will be calculated by averaging the daily totals for each year.

\subsection{Specification and Operationalization of Variables}

In our framework, the dependent variable is crop yield in pounds per acre or bushels per acre. USDA-National Agricultural Statistics Service NASS reports yield as the total production per harvested acre. The independent variables are climatic variables, fertilizer used and technology. Minimum temperature is defined as the lowest temperature recorded during a specified period, usually 24 hours (National Oceanic and Atmospheric Administration's National Weather Service NOAA NWS, 2009).

For this framework, the average annual minimum temperature variable in ${ }^{\circ} \mathrm{C}$ was calculated by adding the total daily minimum temperature for a year and dividing the value by 365 . Maximum temperature is defined as the highest temperature recorded during a specified period of time, usually 24 hours (NOAA NWS, 2009). For this framework, the average annual maximum temperature variable in ${ }^{\circ} \mathrm{C}$ is calculated by adding the total daily maximum temperature for a year and dividing the value by 365. NOAA NWS (2009) defines precipitation as the process whereby water vapor condenses in the atmosphere to form water droplets that fall to the Earth as rain, sleet, snow, hail, etc. 
For the proposed framework, the average annual precipitation variable in millimeters $(\mathrm{mm})$ is calculated by adding the daily precipitation for a year and dividing the value by 365 . Fertilizer used for each of the crops is allocated based on the harvested acreage and nutrient requirements. Harvested acres are used in the computation because data on planted acres were not available for soybean and peanut.

The proposed framework assumes that the triple twenty i.e. 20:20:20 fertilizer containing $20 \%$ nitrogen $(\mathrm{N}), 20 \%$ diphosphorus pentoxide $\left(\mathrm{P}_{2} \mathrm{O}_{5}\right)$ and $20 \%$ potassium oxide $\left(\mathrm{K}_{2} \mathrm{O}\right)$ was used for cotton and corn, while the 0:20:20 containing $20 \% \mathrm{P}_{2} \mathrm{O}_{5}$ and $20 \% \mathrm{~K}_{2} \mathrm{O}$ is conventionally used for soybean and peanut since these are nitrogen fixing plants and do not require much fertilizer in the form of nitrogen. Fertilizers sold in the United States list the percentage of phosphorus as $\mathrm{P}_{2} \mathrm{O}_{5}$ and potassium as $\mathrm{K}_{2} \mathrm{O}$. Therefore, 20:20:20 really contains 20\% nitrogen, $8.6 \%$ phosphorus (actual P), and 16.6\% potassium (actual K) (Argo, 2003).

Time is used in the proposed framework as a proxy for technology, with the assumption that the level of technology increases as the years progress. This is a vector which includes machinery and equipment, improved seeds, better management practices, and it is used to assess farmer's adaptive capacity (Ajetomobi and Abiodun, 2010). Kouka and Engle (1998) explained that the concept of time helps the understanding of production and supply dynamics. They explained that the time lag between different production periods is strongly influenced by the underlying technology. They suggested the consideration of technological and biological lags in explaining the production and supply functions. In estimating catfish supply in US market, they used time as a proxy for technological change. Also, Chavas and Johnson (1982) introduced time in explaining the production and supply dynamics of US broilers and turkeys. They explained that the time separating two successive production periods is strongly influenced by the underlying technology.

\subsection{Data Analysis}

Trend and correlation analyses will be used for the assessment of the climatic timeseries data and crop yield. LIMDEP version 8.0 will be used for the OLS multiple regression analysis. The crop yield for the four crops will be regressed against the independent variables: minimum temperature, maximum temperature, precipitation, fertilizer used, and technology. The functional relationship between the dependent variable and the independent variables will be estimated and the explanatory power of the OLS regression equation tested using the concept of coefficients of determination, or how much of the variation in yield is explained by the independent variables.

\section{Summary and Conclusion}

The overall objective of this research is to propose a theoretical framework for assessing the effects of climatic variables such as minimum temperature, maximum temperature and precipitation, technology and fertilizer used on historical yields of the four major crops in Alabama - cotton, corn, peanut and soybean the availability of consistent time-series data on climatic and economic variables. The specific objectives are to: i) assess the strength of the relationship between crop yield and 
selected climatic variables such as minimum temperature, maximum temperature, precipitation, and variables such as fertilizer used and technology, and ii) assess farmers' adaptive capacity to such changes in Alabama.

Literature suggests that variables such as climatic and economic changes impact crop yield. Our research makes several contributions to research as well as practice. Firstly, we presented a review of extant research, and proposed a framework for assessing the impact of climate change on crop yields. One major research contribution is to shed light on the relationships between these variables, to encourage the adoption of appropriate technology for increased crop yield. Moreover, the validly of our theoretical framework can be established through empirical testing. Our proposed framework is expected to aid stakeholders in the agricultural sector, including farmers, planners, policy-makers, outreach and extension educators, public relations experts, as well as consumers of agricultural produce.

\section{References}

1. Adger, W., Agrawala, S., Mirza, M., Conde, C., O’Brien, K., Pulhin, J., Pulwarty, R., Smit, B., \& Takahashi, K. (2007). Assessment of adaptation practices, options, constraints and capacity.

2. Adger, W.N. (2006). Vulnerability. Global Environmental. Change, 16(3), 268281.

3. Adger, W.N., \& Vincent, K. (2005). Uncertainty in adaptive capacity. (IPCC Special issue on Describing uncertainties in climate change to support analysis of risk and options) Comptes Rendus Geosci, 337(4), 399-410.

4. Ajetomobi, J., \& Abiodun, A. (2010). Climate Change Impacts on Cowpea Productivity in Nigeria. African Journal of Food, Agriculture, Nutrition and Development, 10(3).

5. Argo, B. 2003. Understanding pH management and plant nutrition Part 3. Journal of the International Phalaenopsis Alliance, 13(2).

6. Auffhammer, M., Ramanathan, V., \& Vincent, J.R. (2012). Climate change, the monsoon, and rice yield in India. Climatic Change. 111, 411-424.

7. Ayanlade, A., Radeny, M., \& Morton, J.F. (2017). Comparing smallholder farmers' perception of climate change with meteorological data: A case study from southwestern Nigeria. Weather and Climate Extremes. 15, 24-33.

8. Barrios, S., Ouattara, B., \& Strobl, E. (2004). The impact of climatic change on agricultural production: Is it different for Africa? Munich Personal RePEc Archive MPRA Paper No. 9240.

9. Bunn, C., Läderach, P., Ovalle Rivera, O., \& Kirschke, D. (2015). A bitter cup: Climate change profile of global production of Arabica and Robusta coffee. Climatic Change, 129, 89-101.

10. Cai, X., Wang, D., \& Laurent, R. (2009). Impact of climate change on crop yield: A case study of rainfed corn in central Illinois. Journal of Applied Meteorology and Climatology, 48(9), 1868-1881.

11. Chaney, P. (2007). Climate. In encyclopedia of Alabama. http://www.encyclopediaofalabama.org/article/h-1283.

12. Changnon, S., \& Hollinger, S. (2003). Problems in estimating impacts of future climate change on Midwestern corn yields. Climatic Change, 58, 109-118. 
13. Chavas, J., \& Johnson, S.R. (1982). Supply dynamics: The case of U.S. broilers and turkeys. American Journal of Agricultural Economics, 64, 558-564.

14. Chen, C., McCarl, B., \& Schimmelpfennig, D. (2004). Yield variability as influenced by climate: A statistical investigation. Climate Change66, 239-261.

15. DAFF. (2005). Information handbook: Exceptional circumstances assistance. Australian Government Department of Agriculture, Fisheries and Forestry. http://www.affa.gov.au/content/publications.cfm?ObjectID=D43AC96E-FEB942A0- 9A6BBCD98FA5A401

16. DAFF. (2006). National agriculture and climate change action plan 2006-2009. Department of Agriculture, Fisheries and Forestry, Canberra.

17. Deressa, T., \& Hassan, R. (2009). Economic impact of climate change on crop production in Ethiopia: Evidence from cross-section measures. Journal of African Economies, 18, 529-554.

18. Diaz-Ambrona, C., Pazos, R., \& Tovar, C. (2004). Global climate change and food security for small farmers in Honduras. $4^{\text {th }}$ International Crop Science Congress. http://www.cropscience.org.au/icsc2004/ poster/2/6/941_diazambronacgh.htm

19. Dixon, R. (2009). Peanut production in Alabama. Encyclopedia of Alabama. http://www.encyclopediaofalabama.org/article/h-2016

20. du Toit, A.S., \& Prinsloo, M.A. (2001). El Niño-southern oscillation effects on maize production in South Africa: A preliminary methodology study. (eds.). In Impacts of El Niño and Climate Variability on Agriculture, ASA Special Publication, American Society of Agronomy 63, 77-86.

21. Food and Agriculture Organization of the United Nations. (1996). Agroecological zoning: Guidelines, FAO soils bulletin, 73, Rome, Italy.

22. Frich, P., Alexander, L., Della-Marta, P., Gleason, B., Haylock, M., Klein-Tank, A., \& Peterson, T. (2002). Observed coherent changes in climatic extremes during the second half of the twentieth century. Climate Research, 19, 193-212.

23. Goldblum, D. (2009). Sensitivity of corn and soybean yield in Illinois to air temperature and precipitation: The potential impact of future climate change. Physical Geography, 30, 27-42.

24. Gwimbi, P. (2009). Cotton farmers' vulnerability to climate change in Gokwe District (Zimbabwe): Impact and influencing factors. JAMBA: Journal of Disaster Risk Studies, 2(2).

25. Harrison, A. (2010). An assessment of climate change on grain production in Belize. Unpublished thesis, Tuskegee University.

26. Harvey, C.A., Rakotobe, Z.L., Rao, N.S., Dave, R., Razafimahatratra, H., Rabarijohn, R.H., Rajaofara, H., \& Mackinnon J.L. (2014). Extreme vulnerability of smallholder farmers to agricultural risks and climate change in Madagascar. Philosophical Transactions of the Royal Society B: Biological Sciences, 369(1639), 20130089. https://doi.org/10.1098/rstb.2013.0089

27. Hijmans, R. (2003). The effect of climate change on global potato production. American Journal of Potato Research, 80, 271-280.

28. Hu, Q., \& Buyanovsky, G. (2003). Climate effects on corn yield in Missouri. Journal of Applied Meteorology, 42, 1626-1635.

29. Intergovernmental Panel on Climate Change, IPCC. (2007). Climate change: Impacts, adaptation and vulnerability, contribution of working group ii to the 
fourth assessment report of the intergovernmental panel on climate change. Cambridge, UK: Cambridge University Press.

30. Knox, J., Hess, T., Daccache, A., Wheeler, T. (2012). Climate change impacts on crop productivity in Africa and South Asia. Environmental Research Letters. 7, 034032. https://doi.org/10.1088/1748-9326/7/3/034032

31. Kouka, P., \& Engle, C. (1998). An estimation of supply in the catfish industry. Journal of Applied Aquaculture, 8(3)

32. Kreft, S., Eckstein, D., \& Melchior, I. (2017). Global climate risk index. Who suffers most from extreme weather events? Weather-related loss events in 2015 and 1996 to 2015 [Internet]. Germanwatch Nord-Sud Iniative eV. www.germanwatch.org/en/cri

33. Kucharik, C., \& Serbin, S. (2008). Impacts of recent climate change on Wisconsin corn and soybean yield trends. Environmental Research Letters, 3, 034003 .

34. Kurukulasuriya, P., \& Mendelsohn, R., (2008). A Ricardian analysis of the impact of climate change on African cropland. African Journal of Agricultural and Resource Economics, 2.

35. Lee, J., De Gryze, S., \& Six, J. (2009). Effect of climate change on field crop production in the Central Valley of California. California Energy Commission, Sacramento, California.

36. Li, Y., Ye, W., Wang, M., \& Yan, X. (2009). Climate change and drought: A risk assessment of crop-yield impacts. Climate Research, 39, 31-46.

37. Lobell, D., Cahill, K., \& Field, C. (2007). Historical effects of temperature and precipitation on California crop yields. Climatic Change, 81, 187-203.

38. Lobell, D., \& Field, C. (2007). Global scale climate-crop yield relationships and the impacts of recent warming. Environmental Research Letters 2, 014002.

39. Lobell, D., Ortiz-Monasterio, J., Asner, G., Matson, P., Naylor, R., \& Falcon, W. (2004). Analysis of wheat yield and climatic trends in Mexico. Field Crops Research, 94, 250-256.

40. Makhado, J. M. (1996). Potential effects of climate change on corn production in Zimbabwe. Climate Research, 6, 147-151.

41. Mendelsohn, R., Nordhaus, W., \& Shaw, D. (1994). The impact of global warming on agriculture: A Ricardian analysis. American Economic Review, 84, 753-71.

42. Mendelsohn, R., \& Tiwari, D. (2000). Two essays on climate change and agriculture: A developing country perspective. Food and Agriculture Organization of the United Nations (FAO) Economic and Social Development Paper 145. Rome, Italy.

43. Morton, J.F. (2007). The impact of climate change on smallholder and subsistence agriculture. Proceedings of the national academy of sciences 104 , 19680-19685.

44. Molua, E., \& Lambi, C. (2007). The economic impact of climate change on agriculture in Cameroon. World Bank Policy Research Working Paper 4364.

45. National Oceanic and Atmospheric Administration's National Weather Service. (2009). National weather service glossary. http://www.nws.noaa.gov/glossary/ 
46. Nelson, G.C., Rosegrant, M.W., Koo, J., Robertson, R., Sulser, T., Zhu, T., Ringler, C., Msangi, S., Palazzo, A., Batka, M., Magalhaes, M., ValmonteSantos, R., Ewing, M., \& Lee, D. (2009). Climate change: Impact on agriculture and costs of adaptation. International Food Policy Research Institute IFPRI, Food Policy Report.

47. Nelson, D., Adger, W., \& Brown, K. (2007). Adaptation to environmental change: Contributions of a resilience framework. Annual Review of Environmental Resources, 32, 395-419

48. Nelson, R., Kokic, P., Crimp, S., Meinke, H., Howden, S.M. (2010). The vulnerability of Australian rural communities to climate variability and change: Part I - Conceptualising and measuring vulnerability. Journal of Environmental Science \& Policy, 13. https://doi: 10.1016/j.envsci.2009.09.006

49. Nelson R., Kokic, P., Meinke, H., (2007). From rainfall to farm incomes transforming advice for Australian drought policy. II. Forecasting farm incomes. Australian Journal of Agricultural Research, 58(10), 1004-1012

50. Ning, Z.H., \& Abdollahi, K. (2004). Gulf coast regional climate. GCRCC and LSU Graphic Services.

51. Olesen, J., \& Bindi, M. (2004). Agricultural impacts and adaptations to climate change in Europe. Farm Policy Journal. 1, 36-46.

52. Parry, M., Rosenzweig, C., Iglesias, A., Livermore, M., \& Fischer, G. (2004). Effects of climate change on global food production under SRES emissions and socio-economic scenarios. Global Environmental Change, 14, 53-67.

53. Parry, M.L., Canziani, O.F., Palutikof, J.P., van der Linden, P.J., \& Hanson, C.E. (Eds.), (2007). Climate change: Impacts, adaptation and vulnerability. contribution of working group II to the fourth assessment report of the intergovernmental panel on climate change (pp. 717-743). Cambridge, UK: Cambridge University Press.

54. Peng, S., Huang, J., Sheehy, J., Laza, M., Visperas, R., Zhong, X., Centeno, G., Khush, G., \& Cassman, K. (2004). Rice yields decline with higher night temperature from global warming. PNAS 101, 9971-9975.

55. Rosenzweig, C., \& Hillel, D. (1995). Potential impacts of climate change on agriculture and food supply consequences. The Nature and Implications of Environmental Change, 1(2).

56. Rosenzweig, C., Tubiello, F., Goldberg, R., Mills, E., \& Bloomfield, J. (2002). Increased crop damage in the US from excess precipitation under climate change. Global Environmental Change 12, 197-202.

57. Russell, N. (2007, April). The agricultural impact of global climate change: How can developing-country farmers cope? Geotimes, Earth, Energy and Environmental News.

58. Schlenker, W., \& Lobell, D. (2010). Robust negative impacts of climate change on African agriculture. Environmental Research Letters, 5, 014010.

59. Schmidhuber, J., \& Tubiello, F. (2007). Global food security under climate change. Proceedings of the National Academy of Sciences of the USA, PNAS 104(50), 19703-19708. 
60. Schroth, G., Läderach, P., Martinez-Valle, A.I., \& Bunn, C. (2017). From sitelevel to regional adaptation planning for tropical commodities: Cocoa in West Africa. Mitigation and Adaptation Strategies for Global Change, 22, 903-927. https://doi.org/10.1007/s11027-016-9707-y

61. Smit, B., Ludlow, L., \& Brklacich, M. (1988). Implications of a global climatic warming for agriculture: A review and appraisal. Journal of Environmental Quality, 17, 519-27.

62. Srivani, O., Geethalakshmi, V., Jagannathan, R., Bhuvaneswari, K., \& Guruswamy, L. (2007). Impact of future climate change on growth and productivity of rice crop in Tamil Nadu. Asian Journal of Agricultural Research, 1, 119-124.

63. Travasso, M., Magrin, G., Rodriguez, G., Solman, S., \& Nunez, M. (2009). Climate change impacts on regional maize yields and possible adaptation measures in Argentina. International Journal of Global Warming, 1, 201-213.

64. Tao, S., Xu, Y., Liu, K., Pan, J., \& Gou, S. (2011). Research progress in agricultural vulnerability to climate change. Collection of Advances in Climate Change Research, 2(4), 203-210. https://doi.org/10.3724/ SP.J.1248.2011.00203.

65. Tuttolomondo, T., La Bella, S., Lecardane, G., \& Leto, C. (2009). Simulation effects of climate change on barley yields in rural Italy. http://www.fao.org/fileadmin/templates/ess/pages/rural/wye_city_group/2009/P aper_5_2_Lecardane_Simulation_of_the_effects_of_climate_change_on_barley _yields_in_rural_I taly.pdf

66. United States Department of Agriculture. (2007). Census of Agriculture, Alabama State and County Data._USDA National Agricultural Statistics Service, US Department of Agriculture. http://www.agcensus. usda.gov/ Publications/2007/ Full_Report/ Volume_1,_Chapter_1_State_ Level/Alabama/indexasp

67. United States Department of Agriculture. (2008). State Agriculture Overview, page 1. Alabama Agricultural Statistics Service. US Department of Agriculture. http://www.nass.usda.gov/ Statistics_by_State/ Ag_Overview/AgOverview AL.pdf

68. United States Department of Agriculture. (2012). Climate change and agriculture in the United States: Effects and adaptation. USDA Technical Bulletin 1935. Washington, DC. US Department of Agriculture.

69. United States Department of Agriculture. (2016). Crop Yield Data from 19602005. National Agricultural Statistics Service - Quick Stats. US Department of Agriculture. http://www.nass.usda.gov/QuickStats/Create_County_All.jsp

70. Wagaw, M., G. Kebede, and W. Tadesse. (2009). Adapting the climate change Wet season rain: Harvesting for dry spell irrigation in Alabama. Geological Society of America. 41, 72,15

71. Wiréhn, L., Danielsson, A., \& Neset, T.S., (2015). Assessment of composite index methods for agricultural vulnerability to climate change. Journal of Environmental Management, 156 (1), 70-80. 
72. Xiao, X., Melillo, J., Kicklighter, D., McGuire, A., Tian, H., Pan, Y., Vörösmarty, C., \& Yang, Z. (2002). Transient climate change and potential croplands of the world in the $21^{\text {st }}$ century. Massachusetts Institute of Technology, Joint program on the Science and Policy of Global Change, Report No. 18.

73. Yingjie, L., \& Erda, L. (2008). Impact of climate warming in the past 20 years on agriculture in different regions of China. Advances in Climate Change Research, Article ID:1673-1719, Suppl. 0051-55

74. Zhai F., Lin, T., \& Byambadorj, E. (2009). A general equilibrium analysis of the impact of climate change on agriculture in the People's Republic of China. MPRA Paper No.21127.

75. Zhai, F., \& Zhuang, J. (2009). Agricultural impact of climate change: A general equilibrium analysis with special reference to Southeast Asia. ADBI Working Paper, No.131. Tokyo: Asian Development Bank Institute. http://www.adbi.org/workingpaper/2009/02/23/2887.agricultural.impact.climate. change/

\section{About Our Authors}

Oluwagbemiga Ojumu is an Assistant Professor of Economics and Statistics at Prairie View A\&M University. He has presented and published peer reviewed scholarly research work at various conferences and Journals reflecting interests in development Economics, Demand and Supply Responses, International Trades, Labor Productivity, Innovation Economics, and Agricultural and Environmental Economics. He is an experienced grant writer with several successful grants from various agencies including United States Department of Agriculture, National Science Foundation, and Health Resources and Services Administration.

Modupe Ojumu is an Economics Instructor at Prairie View A\&M University. She has presented peer reviewed scholarly research at different conferences and published in peer reviewed journals, that reflect Economic development, Agricultural and Environmental Economics, Consumer Choices, and International Trade.

Kishwar Joonas is a tenured Associate Professor of Marketing at Prairie View A\&M University. Dr. Joonas has presented peer-reviewed scholarly research, and published in eminent conferences and journals. Her research interests include Consumer Behavior, Cross-cultural Marketing, Flow Theory, Environmental and Healthcare Marketing, Statistical Modeling, as well as Marketing Education. Her research outlets include prestigious publications such as Asia-Pacific Journal of Management, Health Marketing Quarterly, Technology in Society, AIMS International Journal of Management, Hospital Topics, and Journal of Higher Education Theory and Practice. She has over 21 years of experience in teaching, research, as well as university and professional service. 